\title{
Orienteering competition injuries: injuries incurred in the Finnish Jukola and Venla relay competitions
}

\author{
P E Linko, H K Blomberg, H M Frilander
}

\begin{abstract}
Objectives-The aim of this study was to find out the amount, type, and localisation of acute orienteering injuries in the 1995 Finnish Jukola (men's) and Venla (women's) relay competitions with 9724 participants.

Methods-Patient data were collected on a preplanned form at the first aid station.

Results-There were 244 acute competition injuries. The overall injury incidence was $2.5 \%$ (95\% confidence interval (CI) 2.2 to 2.8$), 2.3 \%$ in the men's relay and $3.2 \%$ in the women's relay, and the difference between incidences among men and women was statistically significant (odds ratio (OR) $1.4 ; 95 \%$ CI 1.1 to 1.9 ). The injury rates were also calculated per 1000 competition hours and per $1000 \mathrm{~km}$ and were 15.4 and 2.6 respectively. Most of the injuries could be treated at the first aid station. Female orienteers had more blisters (OR 4.4; 95\% CI 2.5 to 7.9) and fewer wounds (OR $0.5 ; 95 \%$ CI 0.2 to 1.0 ) than male orienteers. Injuries occurred mostly in the lower extremities $(\mathbf{7 0} \%)$, and ankle sprains accounted for $25 \%$ of all injuries. Injuries were more common during the first leg of both relays.

Conclusions-This study shows the heavy workload in a first aid station of a big orienteering relay competition. It indicates a difference in injuries between the sexes and in the different stages of the relay, which should be further investigated in order to prevent orienteering competition injuries.

(Br F Sports Med 1997;31:205-208)
\end{abstract}

Keywords: orienteering; acute injuries; injury incidence

General Practice and

Primary Health Care,

Helsinki University

H K Blomberg

Dragsvik Garrison

Hospital

H M Frilander

Correspondence to: H K Blomberg, Department of General Practice and Primary Health Care, $P O$ Box 50, FIN

00014,University of Helsinki, Finland.

Accepted for publication 28 May 1997 pionships in 1981. Korpi et al studied the injuries in a five day FIN-5 event in 1984 and the Finnish night orienteering championships in 1985. McLean ${ }^{3}$ presented data on first aid visits at the Scottish six day event in 1989 and the Jan Kjellström memorial event in 1990. Hintermann and Hintermann ${ }^{4}$ studied the injuries requiring first aid treatment during the Swiss six day event in 1991. In these races there were 1.4-5.3 injuries per 100 competitors. Ekstrand $e t$ at investigated the injuries in the Swedish O-ringen five day event in 1987, and the total incidence of all injuries was $7.3 / 1000$ competition hours.

Most of the injuries in these studies were mild cuts and wounds. Ankle sprain is a typical injury in orienteering accounting for 15-24\% of acute competition injuries. ${ }^{356}$ No differences between male and female orienteers with regard to injury rates have been found. ${ }^{278}$ Almost all patients could be treated in the first aid stations, and only $1.6-2.6 \%$ had to be admitted to hospital for further investigations. ${ }^{24}$

Jukola relay is a seven leg relay competition at night for male orienteers, and Venla relay is a four leg daytime relay for women. Both relays have a mass start. These are the biggest one day orienteering events in Finland. Among the competitors there are both world class orienteers who run for victory and a large number of recreational orienteers.

The aim of this study was to find out the amount, type, and localisation of acute orienteering injuries in the Finnish Jukola and Venla relay competitions.

\section{Methods}

In 1995 the 47th annual "Jukolan viesti" and 18 th "Venlojen viesti" took place in Sipoo, in Southern Finland. There were 9724 participants in 1107 male and 597 female teams from 15 different countries. The women's competition started at 1450 and the men's at 2225. The length of the legs varied in the men's relay from 8.0 to $14.1 \mathrm{~km}$ and altogether the men's course was $75.2 \mathrm{~km}$ long, and in the women's relay the legs varied from 5.5 to $8.2 \mathrm{~km}$ and the whole course was $26.8 \mathrm{~km}$ long. The weather was cloudy and dry. The sun set at 2243 and rose at 0357. The terrain was both technically and physically very demanding, with especially intricate rock shapes and some steep slopes. The terrain was typical for southern Finland: mixed forest where the visibility and "runability" was good except for some slopes with thicker forest and bushes. The terrain was 
similar in all legs. During the three first legs in the men's relay a halogen head lamp was used by most competitors because of dusk and darkness.

The first aid station was near the start/finish area and was continuously manned by at least three doctors, nine nurses, and a physiotherapist. They all worked on a voluntary basis. In the first aid station it was possible to clean and dress wounds, suture cuts, give cooling and taping therapy, and give intravenous fluids and medication. Resuscitation was also possible. Local Red Cross personnel had three additional first aid units without a doctor.

Name, date of birth, gender, address, diagnosis, treatment, registering time, and leaving time were collected on a separate form for each patient at the first aid station. Later the competitor status (competitor/ not competitor) of the patient, the relay leg on which the injury occurred, and the result of the team were checked from the results lists. The ages of the competitors were not registered.

Cross tabulation, $\chi^{2}$ tests, and logistic regression were used in the statistical analyses. Significance was accepted at the $5 \%$ level $(P<0.05)$. A confidence interval of $95 \%(95 \%$ $\mathrm{CI}$ ) is generally shown in connection with statements concerning proportions. The data were processed by the SAS 6.1 and Excel 5.0 software.

\section{Results}

The first aid station was visited by 417 patients of whom 360 were competitors (3.7 visits/ 100 competitors), and 244 (170 men and 74 women) of these were the result of acute trauma in the competition. Officials and spectators made 57 visits to the first aid station.

The injury incidence was $2.5 / 100$ competitors $(2.5 \%)$. The incidence of competition injuries was higher in women $(3.2 \%)$ than in men $(2.3 \%$ ) (odds ratio (OR) $1.4 ; 95 \%$ CI 1.1 to 1.9). The fastest female team was in the forest for 3.3 hours, the slowest for 8.5 hours, the total exposure time was 2728 hours and the injury rate was $27.1 / 1000$ competition hours. The fastest time in the men's relay was 9.0 hours, the slowest 28.3 hours, the total exposure time was 13086 hours and the injury rate was $13.0 / 1000$ competition hours. The women's injury rate was higher than the men's even when the competition time was considered (OR 2.1; 95\% CI 1.6 to 2.8 ). The overall injury rate was $15.4 / 1000$ competition hours. In the women's relay the total distance run was $15202 \mathrm{~km}$ and the injury rate was $4.9 / 1000$ $\mathrm{km}$, and in the men's relay the total distance was $79973 \mathrm{~km}$ and the injury rate was $2.1 / 1000 \mathrm{~km}$. On an average competition kilometre, the risk of injury to women was higher than to men (OR $2.3 ; 95 \%$ CI 1.7 to 3.0 ). The overall injury rate was $2.6 / 1000 \mathrm{~km}$.

Figure 1 shows the workload of the first aid station. About one hour after both starts there was a rise in the number of patients contacting the first aid station. Most of the visits were caused by competition injuries in the race. Competitors also contacted the first aid station with other medical problems (competitors treated for other reason)-for example, allergies, headache, infections, and injuries incurred before the competition. Also officials and spectators (non-competitors treated) were treated at the first aid station for similar reasons. Most of the visits made for reasons other than competition injuries took place before the men's race.

The risk of injury was significantly greater during the first leg than the last leg in both relays. In the men's relay the risk of injury seemed to decrease from the first to the last leg (table 1).

Competition injuries occurred most commonly in the lower extremities (70\%). The most frequent injuries were blisters in women and small wounds in men (table 2). Women had

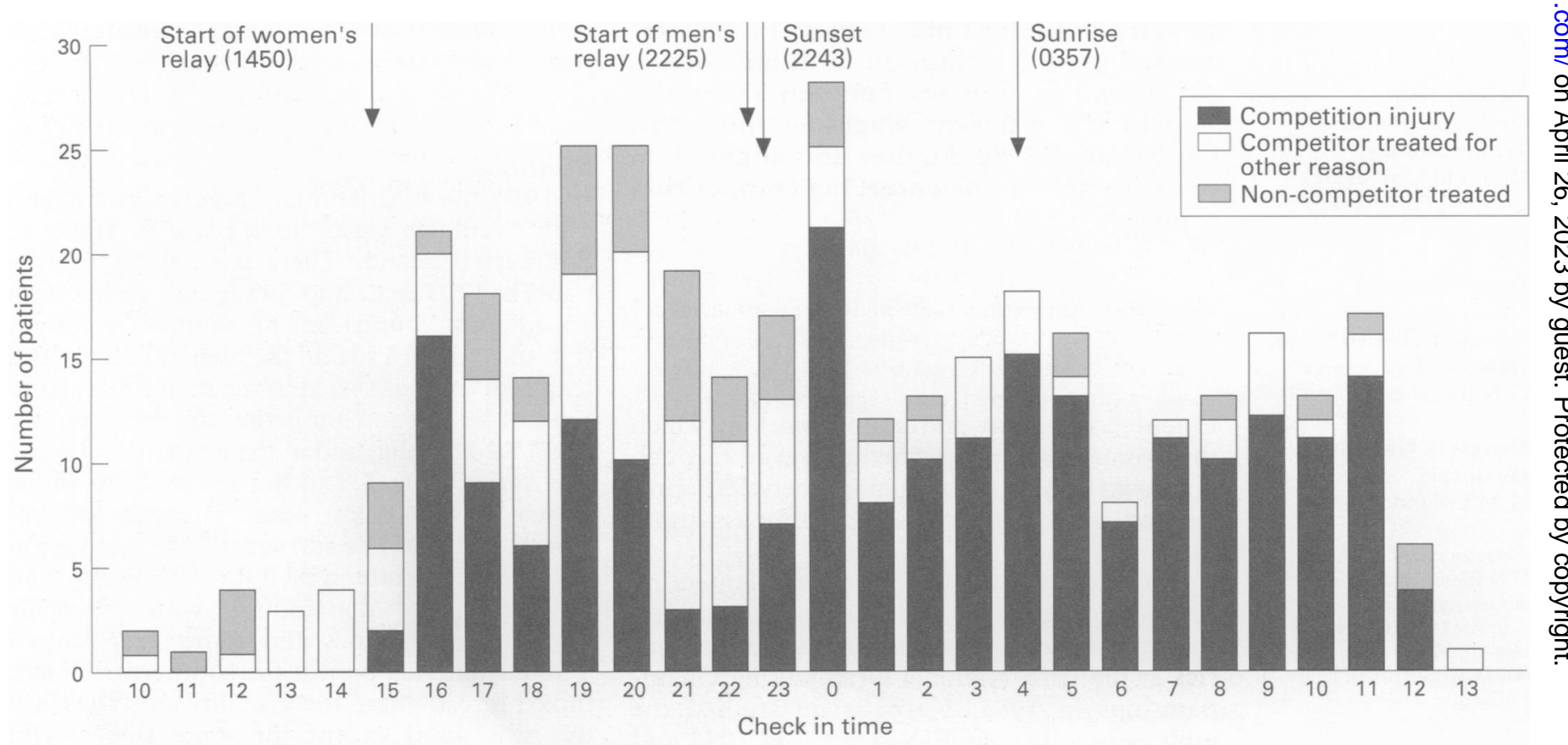


Table 1 Competitor's risk of injury in different legs of the relay

\begin{tabular}{|c|c|c|c|c|c|c|c|}
\hline & \multirow[b]{2}{*}{ Leg } & \multirow{2}{*}{$\begin{array}{l}\text { Mean leg } \\
\text { distance (km) }\end{array}$} & \multicolumn{2}{|c|}{ Competiors } & \multirow[b]{2}{*}{ Odds ratio * } & \multirow{2}{*}{$\begin{array}{l}95 \% \text { Confidence } \\
\text { interval }\end{array}$} & \multirow{2}{*}{$\begin{array}{l}\text { Injury rate } \\
(\text { No/1000 km) }\end{array}$} \\
\hline & & & Total $(n)$ & Injured (n) & & & \\
\hline Men's race & $\begin{array}{l}1 \\
2 \\
3 \\
4 \\
5 \\
6 \\
7\end{array}$ & $\begin{array}{r}9.9 \\
11.8 \\
12.9 \\
8.1 \\
8.1 \\
10.4 \\
14.1\end{array}$ & $\begin{array}{l}1107 \\
1092 \\
1071 \\
1057 \\
1053 \\
1045 \\
1018\end{array}$ & $\begin{array}{l}39 \\
32 \\
27 \\
21 \\
19 \\
14 \\
16\end{array}$ & $\begin{array}{l}1 \\
0.8 \\
0.7 \\
0.6 \\
0.5 \\
0.4 \\
0.4\end{array}$ & $\begin{array}{l}0.5 \text { to } 1.3 \\
0.4 \text { to } 1.2 \\
0.3 \text { to } 1.0 \\
0.3 \text { to } 0.9 \\
0.2 \text { to } 0.7 \\
0.2 \text { to } 0.8\end{array}$ & $\begin{array}{l}3.6 \\
2.5 \\
2.0 \\
2.5 \\
2.2 \\
1.3 \\
1.1\end{array}$ \\
\hline Total & & 75.3 & 7443 & 170 & 1 & & 2.1 \\
\hline Women's race & $\begin{array}{l}1 \\
2 \\
3 \\
4\end{array}$ & $\begin{array}{l}5.6 \\
5.6 \\
7.5 \\
8.1\end{array}$ & $\begin{array}{l}597 \\
577 \\
565 \\
542\end{array}$ & $\begin{array}{l}29 \\
11 \\
21 \\
13\end{array}$ & $\begin{array}{l}1 \\
0.4 \\
0.8 \\
0.5\end{array}$ & $\begin{array}{l}0.2 \text { to } 0.8 \\
0.4 \text { to } 1.3 \\
0.2 \text { to } 0.9\end{array}$ & $\begin{array}{l}86 \\
34 \\
50 \\
30\end{array}$ \\
\hline Total & & 26.8 & 2281 & 74 & $1.4 \dagger$ & 1.1 to 1.9 & 4.9 \\
\hline
\end{tabular}

* Odds of getting injured compared with the first leg.

+ Women's odds of getting injured compared with the odds of the men.

Table 2 Competition injuries among men and women. Numbers in parentheses are percentages

\begin{tabular}{llllllll}
\hline & Injury & & & & & \\
\cline { 2 - 8 } Gender & Wound & Bruises & Blisters & Sprain & Eye injury & Other & Total \\
\hline Men & $56(33)$ & $26(15)$ & $20(12)$ & $52(31)$ & $12(7)$ & $4(2)$ & $170(100)$ \\
Women & $8(11)$ & $12(16)$ & $27(36)$ & $22(30)$ & $5(7)$ & $0(0)$ & $74(100)$ \\
Total & $64(26)$ & $38(16)$ & $47(19)$ & $74(30)$ & $17(7)$ & $4(2)$ & $244(100)$ \\
\hline
\end{tabular}

$\chi^{2}=27.774, \mathrm{df}=5, P<0.0001$.

significantly more blisters (OR 4.4; 95\% CI 2.5 to 7.9) and fewer wounds (OR $0.5 ; 95 \%$ CI 0.2 to 1.0$)$ than men. Ankle sprains accounted for $25 \%(n=60)$ of all competition injuries, and there were 3.8 ankle sprains $/ 1000$ competition hours and 0.6 ankle sprains $/ 1000 \mathrm{~km}$.

In the men's relay the risk of getting sprains was greatest during the first leg (7 of 52) and differed significantly from all other legs except the third and the fifth. Most of the sprains (42 of 52) were ankle sprains and most of these (15) occurred during the first leg of the men's relay. There were more wounds in the first three legs in the men's relay but the difference was not statistically significant. The injury rate did not correlate with the result of the team.

Fifteen men and one woman had to stop the race because of injury. These competitors had 11 ankle sprains (69\%), two wounds, one shoulder and one elbow dislocation, and one shin contusion.

The most frequent treatment procedures were cleaning and dressing small cuts and bruises, cooling therapy, taping of ligament or muscle injuries, and wound suturation. The most frequently ordered drugs were antiinflammatory analgesics and antiallergy medicines. One 46 year old male orienteer had acute myocardial infarction after finishing his relay leg and was successfully resuscitated from ventricular fibrillation in the finishing area and admitted to a hospital for thrombolytic therapy. Other causes for transferring a patient to a hospital for further examination and treatment were one elbow dislocation, one suspected ankle fracture, one eye wound, acute abdominal pain in one orienteer, and exhaustion of one female orienteer. Thus six or $2.5 \%$ of the injured competitors or $1.4 \%$ of all the patients were taken to a hospital.

\section{Discussion}

The injury incidence of $2.5 \%$ in these relays is comparable with the incidences in individual competitions. ${ }^{1-4}$ In this study we had 15.4 acute injuries $/ 1000$ competition hours. Ekstrand et $a \hat{l}$ reported 7.3 acute injuries/1000 competition hours in a five day race, but the injuries that were treated by personnel other than doctors are not given. Johansson's study of elite orienteers showed 1.3 acute injuries $/ 1000$ training hours during a one year study period. ${ }^{7}$ It is understandable that there are fewer injuries during training, and it is likely that the elite orienteers did not report injuries that did not interrupt their training. In our study there was a higher incidence of injuries among women than men, and this difference was accentuated when the injury rate was related to the competition time or distance. This may indicate that the risk of injury is different during different phases of the race and thus there may be some difficulty in comparing the injury rates in relation to time or distance when there are races of different durations.

Previously no difference in competition injury incidence and type has been found between male and female orienteers. ${ }^{27}$ In the study of Kujala et $a l_{,}^{8}$ which was based on orienteering licence insurance records, women had more ankle sprains and men more wounds. In our study female orienteers had a higher incidence of injuries and they had more blisters than male orienteers, which may be due to inappropriate orienteering shoes or fewer training hours or perhaps women seek first aid 
more quickly than men. As in the study of Kujala et $a l,{ }^{8}$ wounds were more common in male orienteers, which is probably caused by a more direct and aggressive running technique.

In both sexes there was a predominance of injuries during the first leg. It is possible that the physical strain of a mass start and the excitement at the beginning of the relay produced more injuries on the first leg than on other legs. Spiked shoes were not allowed in the first leg in these relay competitions and this eliminated the injuries caused by spikes, but on the other hand it might have resulted in more injuries caused by slippery terrain. In the men's relay, the darkness during the first three legs may also have contributed to a greater incidence of injuries. Although the last legs in both relays were longest, the fewest injuries occurred, which could be explained by the orienteers being spread over a broader time scale when starting this leg.

A consideration of the difference in injuries incurred by women and men and in different stages of the relay may have some importance in the prevention of injuries but this needs more investigation.

Ankle sprain is a typical injury in orienteering. ${ }^{3569}$ In our study, $25 \%$ of injuries were ankle sprains and there was a predominance of ankle sprains in the first leg. Ankle injuries were also the most usual injury that led to discontinuation of the race. Much attention should be given to the prevention of ankle injuries in orienteering, including prophylactic ankle disk training and the use of prophylactic ankle taping or ankle stabilisers. ${ }^{10-12}$

The authors thank Dr Tapani Alkula, Department of Sociology, Helsinki University, for his valuable comments.

1 Folan JM. Orienteering injuries. $\mathrm{Br} \quad \mathrm{f}$ Sports $\mathrm{Med}$ 1982;16:236-40.

2 Korpi J, Haapanen A, Svahn T. Frequency, location, and types of orienteering injuries. Scandinavian fournal of Sport Science 1987;9:53-6.

3 McLean I. First aid for orienteering in Scotland. Scientific fournal of Orienteering 1990;6:55-63.

4 Hintermann B, Hintermann M. Injuries in orienteering. A study of the Swiss 6-days orienteering event. Scientific fournal of Orienteering 1992;8:72-8.

5 Ekstrand J, Roos $H$, Tropp $H$. The incidence of ankle sprains in orienteering. Scientific fournal of Orienteering 1990;6:3-9.

6 Hintermann B, Hintermann M. Ankle sprains in orienteering: a simple injury? Scientific fournal of Orienteerorienteering: a simpl

7 Johansson C. Injuries in elite orienteers. Am 7 Sports Med 1986;14:410-15.

1986,14:410-15. Kujala UM, Nylund T, Taimela S. Acute
orienteering. Int $\mathcal{f}$ Sports Med 1995;16:122-5.

9 Linde F. Injuries in orienteering. $\mathrm{Br} F$ f Sports Med 1986;20:125-7.

10 Tropp H, Askling C, Gillquist J. Prevention of ankle sprains Am $\mathcal{f}$ Sports Med 1985;13:259-62.

11 Rovere GD, Clarke TJ, Yates CS, Burely K. Retrospective comparison of taping and ankle stabilizers in preventin ankle injuries. $A m \mathcal{F}$ Sports Med 1988;16:228-33.

12 Gauffin H, Tropp H, Odenrick P. Effect of ankle disk training on postural control in patients with functional instability of the ankle joint. Int $\mathcal{F}$ Sports Med 1988;9:141-4.

\section{Sports medicine in primary care}

The New England Baptist Hospital sports medicine department organised their first annual course in sports medicine in primary care in 1997. It was a new initiative for them as they had few previous links with family doctors or physiotherapists in the community. The two day course began with continental breakfast at 730 am to gather the participants for the 8 am lecture. The course was designed to make an anatomical tour of all sports injuries of the upper and lower limb, and included back pain for good measure. Orthopaedic surgeons and physiotherapists alternated their presentations so that injury and rehabilitation were covered in tandem. The speakers rattled through the slides so fast that if your attention drifted for a moment you would wake up in a different joint. In mitigation, the hand outs were exceptional and as good as many textbooks.

In the afternoon sessions we were taken to the Bioskills laboratory-an exceptional facility that is a hybrid of an anatomy laboratory and an orthopaedic theatre. After signing a comprehensive medicolegal waiver concerning AIDS, hepatitis, and any other viral agents we dressed in full length waterproof theatre gowns, protective shoes, gloves, and goggles. Inside the laboratory we examined a cadaver, dissected to show the injuries about which we had learnt in the morning. Anatomy seemed much more interesting than it ever did in medical school! In the next room they had arranged cadaveric knees and shoulders to allow us to insert arthroscopes. We revised our surface anatomy, and could inject knees and shoulder joints and see the needle tips on the arthroscope. We closed the afternoon with practical revision of joint examination on human (live!) subjects.

It was a superb, if very concentrated course. The local GPs thought it was expensive at $\$ 425$ for two days and it would be prohibitively expensive to travel from the UK for such a short time, but it was an excellent course, which I would thoroughly recommend. The teaching facility itself is well worth a visit and is one of few similar facilities in the United States.

DOMHNALL MACAULEY 